\title{
Grain Price Volatility in a Small Open Economy
}

\author{
MAURICE J. ROCHE \\ The National University of Ireland, Maynooth, Co. Kildare, Ireland. \\ KIERAN MCQUINN \\ Rural Economy Research Centre, Teagasc, Dublin, Ireland
}

\begin{abstract}
Summary
This paper uses a multivariate vector error-correction generalized autoregressive conditional heteroscedasticity model to investigate the effect of British grain prices on their Irish equivalents. We find that in the long run the law of one price holds and in the short run the model captures the salient features of Irish grain prices. The model is used to compute rolling forecasts of the conditional means, variances and covariance of Irish grain prices one year ahead. We find that this model produces superior forecasts compared to those based on a commonly used methodology of an autoregressive conditional mean model where the second moments are estimated using a fixed weight moving average.
\end{abstract}

Keywords: Grain Price Risk, Multivariate GARCH

JEL classification: C32, F31, G15, Q14

Corresponding Author:

Dr. Maurice J. Roche

Department of Economics,

National University of Ireland, Maynooth

Co. Kildare, Ireland.

Telephone: +353-(0) 1-7083786

Fax: +353-(0) 1-7083934

E-mail: Maurice.Roche@may.ie

Website: www.may.ielacademicleconomics

Acknowledgement

We would like to thank Gerry Boyle (NUI Maynooth), Tom Flavin (NUI Maynooth) and Paul Kelly (Teagasc, Dublin) for comments on an earlier draft. We assume full responsibility for any remaining shortcomings. The research was support in part by European Stimulus Funds. 


\section{Introduction}

The policy environment facing European Union (EU) grain producers has undergone considerable change since 1992. The 1992 MacSharry reforms of the EU's Common Agricultural Policy (CAP) reduced grain intervention prices by 30 per cent over a three-year period commencing with the 1993-1994 marketing year. The recent Agenda 2000 reforms yielded a further reduction of 15 per cent in grain intervention prices over a two-year period. A priori, one would expect that this reduction in guaranteed support prices and the consequent movement of internal EU grain prices towards equivalent world prices ${ }^{1}$ would increase the volatility of the price series faced by the producer. $^{2}$

The increased relevance of uncertainty in the decision-making processes of producers has led to traditional supply response models being expanded to incorporate price uncertainty. Recent theoretical research by Coyle (1992) and Saha (1997) on the supply response of producers has adopted the popular mean-variance behavioural postulate. In order to apply these theoretical models estimates of the expected price, variance and covariance among prices of the commodities are required. For example, Oude Lansink (1999) applied their theoretical methodology to land allocation on Dutch arable farms and produced the moment estimates following the econometric methodology of Chavas and Holt (1990). The expected price is obtained using an AR(1) model and the expected variances and covariance of prices are obtained using a fixed weight moving average. We argue that the Chavas and Holt (1990) methodology is too ad hoc given the fact that in the last fifteen years there have been many developments in the time series literature for the purpose of estimating conditional first and second order moments. In particular, the multivariate generalized autoregressive conditional heteroscedasticity (MVGARCH) framework allows for the modeling of both the time varying conditional variances and covariances of prices. 
In the light of these policy and methodological developments, this paper seeks to answer two questions. The first question is what are the salient features of the dynamics of Irish feed barley and wheat prices per tonne? Given that Ireland is a small open economy we assume the law of one price (LOP) holds between British and Irish grain prices. We test the data to examine whether the conditional mean relationship between British and Irish grain prices can be characterized by a vector error correction (VEC) model. The land allocation decision of domestic grain producers requires not only the expected price but also the expected variance and covariance of domestic feed barley and wheat prices. Thus the VEC model is expanded to allow for the modeling of the time varying second moments of domestic feed grain prices using a MVGARCH model. Our findings indicate that the estimated VEC-MVGARCH model adequately describes the dynamics of Irish feed barley and wheat prices using monthly data from January 1982 to March 2001.

The second question is how well do the one-year ahead forecasts of the conditional first and second moments from the VEC-MVGARCH model compare with those generated using the Chavas and Holt (1990) methodology? Irish grain producers typically harvest in AugustOctober and plant wheat in October. Therefore we use a variant of the VEC-MVGARCH model to compare the one-year ahead (October to the following September) rolling forecasts of conditional first and second moments of domestic feed grain prices for the 1990-2000 period with those generated using the Chavas and Holt (1990) methodology. We test whether there is a significant difference in these forecasts using Hansen’s (2001) recently developed test of superior predictive ability (SPA). The SPA tests indicate that the VEC-MVGARCH produces superior forecasts to those produced using the Chavas and Holt (1990) methodology regardless of whether loss functions using either mean squared error or mean absolute deviations are employed. 
The remainder of the paper is organized as follows. In Section 2 we describe the VECMVGARCH model of Irish feed barley and wheat prices based on the theory of the law of one price. The results and analysis is presented in Section 3. A final section offers conclusions.

\section{Modeling the Mean and Volatility of Irish Grain Prices}

Ireland is a deficit producer of cereals. Table 1 below details production, domestic use and self-sufficiency ratios ${ }^{3}$ for Irish cereals (barley, wheat and oats) for the crop years 1997-1998, 1998-1999 and 1999-2000. The self-sufficiency ratios for these periods are all less than one hundred per cent. The exact country location of imported cereals is difficult to ascertain, however official trade statistics (from the Irish Central Statistics Office) reveal that over the period 1996-1999 almost seventy-six per cent of imported wheat was sourced from Britain. Trade information ${ }^{4}$ suggests that a similar proportion of barley imports is also sourced from Britain over the same period. The presence of the border between Northern Ireland and the Republic and the resulting continuous flow of cereal trade adds further credence to the notion of the British cereal prices being the chief determinant of equivalent Irish prices. ${ }^{5}$ Finally, whilst the assumption of British cereal prices being the main "driver" of Irish prices is a testable hypothesis econometrically, data on the relevant agri-monetary relationships between Ireland and other EU states was not available. ${ }^{6}$ Thus given that Ireland is a small open economy we assume the law of one price (LOP) holds between British and Irish grain prices.

The relationship between different international commodity prices for the same generic product attracts considerable attention in the literature. The LOP suggests that the only difference in price of a homogeneous good between two different trading blocs should be the cost of transportation between these two blocs. Any other differences should in principle be arbitraged away. Within a European policy context a central tenet of the CAP is the creation 
of a single, barrier-free market in agricultural products. In theory the prevalence of the LOP indicates a fully integrated trading market.

In reality many issues can distort the LOP. International markets are often slow to adjust to new information and to changes in local and global supply and demand conditions due to the significant lags associated with international commodity trade. Consequently, international price linkages may be imperfect and of a dynamic nature. Policy instruments can also distort the trade of a generic product. Discrepancies between market and institutional exchange rates in the EU during the various different exchange rate regimes have persistently lead to pricing anomalies between member states.

In a British and Irish context it was possible to separately specify the MCA adjusted exchange rate between the two countries and thus to estimate the separate effects of the exchange rate as well as the British price on the Irish price level (see Data Appendix for details). In Figures 1 and 2 we present the sterling prices of British and Irish feed wheat and barley prices. The Irish prices are adjusted for monetary compensatory amounts. The prices are wholesale and are monthly covering the period January 1982 to March 2001. Whilst intervention prices were gradually lowered throughout the early 1990's, grain prices internationally remained very steady because of growth in imports from the so-called Asian 'tiger' economies. The rapid financial downturn in these economies allied to the collapse of the Russian markets in 1996-1997 prompted the fall in grain prices worldwide for the latter part of the 1990s. These lower prices have persisted into the new century. From the figures it is apparent that with certain exceptions British and Irish prices track each other quite closely.

The mean and standard deviation for Irish feed wheat and barley price inflation (at annual rates) is presented in Table 2. Note in particular the increase in the standard deviation for wheat and barley annual price inflation between the 1982-1992 and the 1993-2001 time 
periods. The sample was split in 1992 on the basis that the CAP reform of 1992 constituted a significant structural break in the level of volatility existing in commodity prices. The values for the standard deviation strongly suggest an increase in the volatility of grain prices between these two periods.

Price transmission analysis for agricultural commodities generally focuses on the international transmission of the mean price. A standard approach taken is to adopt a vector autoregression or vector error correction model to provide a clearer understanding of the interrelationships between different price levels. Most studies thus concern themselves solely with the relationship between the levels or mean values of the price series. Examples in the agricultural literature include Ardeni (1989), Goodwin and Schroeder (1991), Mohanty et al. (1995), Diakosavvas (1995), Mohanty et al. (1996), and Ghoshray, Lloyd and Rayner (2000). In general these studies conduct preliminary analysis on the relevant price series for the presence of a unit root and subsequently use cointegration techniques to examine the nature of the relationship between the different price series.

There have been many studies on the time series properties of second moments using univariate GARCH models in the agricultural economics literature. The different policy regimes within US agriculture have prompted studies of the effects of various different government programs on volatility in commodity prices (see for example Crain and Lee (1996)). The use of GARCH models in the context of commodity goods analysis has increased considerably over the past ten years. Most of this analysis has been concentrated on the US market ${ }^{7}$. An early example is an analysis of risk in the U.S. broiler sector by Holt and Aradhyula (1990). Yang and Brorsen (1992) use GARCH analysis in addressing nonlinearities in the daily cash prices of seven different agricultural commodity prices. ${ }^{8}$ Holt (1993) adopted a GARCH in Mean model to infer relative risk premia in U.S. beef margins. McKenzie and Holt (1998) used GARCH and ARCH in Mean models to examine market 
efficiency in agricultural futures prices. Weaver and Natcher (2000) using a univariate GARCH model analyse the effect of changes in US market conditions precipitated by changes in US farm programmes on the volatility of agricultural prices.

Despite the fact that the use of GARCH models in agricultural research has increased considerably over the last decade many studies on the international transmission of agricultural prices typically ignore that the conditional variance (and covariances) of the price series could be time varying. In a notable contribution, Natcher and Weaver (1999) note that while the literature is significantly developed in measurements of price volatility in agricultural markets, "less work has addressed the issue of temporal and spatial transmission of volatility”. With the clear increase in the volatility of international commodity prices faced by producers, there is a need to adopt more advanced time-series econometric techniques in the analysis of commodity price transmission relationships. There is a small but growing literature applying multivariate conditional first and second moment models to study international price transmission simultaneously (see for example, Dawson et al. (2000); Haigh and Bryant (2001); Jumah and Kunst (2001)).

Another important reason for the modeling of the second moments of commodity prices lies in the increased popularity of production models under price and output uncertainty (see for example, Coyle (1992); Coyle (1999); Oude Lansink (1999); Boyle and McQuinn (2001)). These models typically require the specification of the mean, variance and covariance of competing product prices. All of these production models under uncertainty use the methodology of Chavas and Holt (1990) to estimate the conditional means, variances and covariances of commodity prices.

We suggest that the conditional mean of Irish grain prices could be estimated using a VEC model and the conditional covariance matrix could be estimated using an MVGARCH model. The VEC model imposes the LOP in the long run. The hypothesized relationship is 
that Irish grain prices are mainly determined by the respective British grain price and the exchange rate between the two countries. Given the 'small open economy' nature of the Irish grain sector these explanatory variables are assumed to be exogenous. The researcher does not have to impose any a priori restrictions on the expectations mechanism. The conditional means of Irish wheat and barley prices are estimated using

$$
\begin{aligned}
& \Delta p_{t}^{w i r}=\alpha^{w}\left(p_{t-1}^{w i r}-\beta_{1}^{w}-\beta_{2}^{w} t-\beta_{3}^{w} p_{t-1}^{w u k}-\beta_{4}^{w} e_{t-1}\right)+\sum_{i=1}^{m_{1}} \delta_{i}^{w} \Delta p_{t-i}^{w i r}+\sum_{i=0}^{m_{2}} \gamma_{i}^{w} \Delta p_{t-i}^{w u k}+\sum_{i=0}^{m_{3}} \theta_{i}^{w} \Delta e_{t-i}+u_{t}^{w} \\
& \Delta p_{t}^{b i r}=\alpha^{b}\left(p_{t-1}^{b i r}-\beta_{1}^{b}-\beta_{2}^{b} t-\beta_{3}^{b} p_{t-1}^{b u k}-\beta_{4}^{b} e_{t-1}\right)+\sum_{i=1}^{m_{4}} \delta_{i}^{b} \Delta p_{t-i}^{b i r}+\sum_{i=0}^{m_{5}} \gamma_{i}^{b} \Delta p_{t-i}^{b u k}+\sum_{i=0}^{m_{6}} \theta_{i}^{b} \Delta e_{t-i}+u_{t}^{b} \\
& {\left[\begin{array}{l}
u_{t}^{w} \\
u_{t}^{b}
\end{array}\right]=\left[\mathbf{u}_{t}\right] \sim \operatorname{MN}\left(0, \mathbf{H}_{t}\right)}
\end{aligned}
$$

The series $p^{\text {wir }}$ is the price of MCA adjusted Irish feed wheat, $p^{\text {wuk }}$ is the price of British feed wheat, $e$ is the punt/sterling exchange rate, $p^{b i r}$ is the price of MCA adjusted Irish feed barley, $p^{b u k}$ is the price of British feed barley, $\mathrm{t}$ is a time trend and the $u^{i}$ are stochastic error terms. All variables are in logarithms. The expressions in brackets are error correction terms representing deviations from the LOP. The $m_{i}$ are the number of growth variables that are added as explanatory variables in the VEC model and are determined by using a combination of minimizing Bayesian Information Criterion (BIC) and ensuring that the residuals are white noise. The conditional covariance matrix, $\mathbf{H}_{t}$, is estimated following Baba et al. (1991) and Flavin and Wickens (2001) using the following MVGARCH(1,1) model

$$
\mathbf{H}_{t}=\mathbf{C}^{\prime} \mathbf{C}+\mathbf{B}^{\prime}\left(\mathbf{u}_{t-1} \mathbf{u}_{t-1}^{\prime}-\mathbf{C}^{\prime} \mathbf{C}\right) \mathbf{B}+\mathbf{A}^{\prime}\left(\mathbf{H}_{t-1}-\mathbf{C}^{\prime} \mathbf{C}\right) \mathbf{A}
$$

In (2) A, B and $\mathbf{C}$ are 2x2 matrices. Equation (2) has the advantage that $\mathbf{H}_{t}$ is guaranteed to be positive definite. A and $\mathbf{B}$ are full symmetric matrices and $\mathbf{C}$ is a lower triangular matrix. $\mathbf{C}^{\prime} \mathbf{C}$ gives the long-run conditional covariance matrix of the monthly growth rate of Irish feed barley and wheat prices. The parameters in $\mathbf{A}$ and $\mathbf{B}$ capture the importance of short-run deviations in the conditional covariance matrix from the long-run values. Under the 
assumption of conditional multivariate normality the model (1)-(2) can be estimated by maximum likelihood or quasi-maximum likelihood methods.

\section{Results and analysis}

We present our analysis in four subsections. The VEC model we estimate requires that all variables be integrated of order one. In Section 3.1 we investigate the time series properties of the variables of interest. The LOP imposes a long-run cointegrating relationship between Irish and British prices and the exchange rate between the two currencies. The cointegration analysis is presented in Section 3.2. Equations (1)-(2) are estimated and analysed in Section 3.3. We use this model to forecast Irish grain prices one-year ahead. These are compared to benchmark forecasts using the methodology of Chavas and Holt (1990). The results are presented in Section 3.4 .

\subsection{Unit root analysis}

We tested the British and Irish feed barley and wheat prices and the punt/sterling exchange rate for unit roots using a variety of unit root testing procedures. In all of the unit root tests

appropriate lag lengths of the adjustment parameters are chosen by reduction methods. ${ }^{9} \mathrm{~A}$ trend term was added to all test regressions for grain prices as they have a noticeable downward trend over the period. The results are reported in Table 3. The standard augmented Dickey and Fuller (1981) (ADF) unit root test would suggest that all series are integrated. However this test lacks power. Maddala and Kim (1998) suggest that two modified ADF tests; one developed by Elliott et al. (1996) and the other a weighted symmetric test developed by Pantula et al. (1994) have more power than the basic ADF test. However these two unit root tests suggest that the series are also nonstationary. Given that there were major CAP reforms in 1992 and 2000 we also performed some tests where the 
alternative hypothesis is one where the series is stationary around a breaking trend. The Zivot and Andrews (1992) unit root tests assume a unit root null hypothesis versus the alternative hypothesis that the series is stationary around a break in its level, a break in its growth rate and a break in both its level and growth rate. The Perron (1997) unit root tests are similar. It is evident from Table 3 that null hypothesis of a unit root is hardly ever rejected at conventional significance levels.

Given the seasonal nature of the grain price series we also test for unit roots at seasonal frequencies using methods described in Franses (1998). These tests are similar to the Hylleberg et al. (1990) tests on quarterly time series. These unit root test statistics are also presented in Table 3. The null hypothesis that $\mathrm{H}_{0}: \pi_{1}=0$ or that the series contains a nonseasonal unit root cannot be rejected using critical values from Franses and Hobijn (1997). However the presence of bi-annual and seasonal unit roots can be rejected. The null hypothesis that $\mathrm{H}_{0}: \pi_{2}=0$ and the null hypothesis that $\mathrm{H}_{0}: \pi_{3}-\pi_{12}=0$ can be rejected for nearly all series. All of the unit root tests suggest that the null hypothesis of a non-seasonal unit root in the levels of all five series cannot be rejected. ${ }^{10}$ Thus in the remainder of our analysis we assume that all of the price and exchange rate variables are I(1).

\subsection{Cointegration analysis}

The hypothesised cointegrating relationships based on the LOP may be unstable given the major CAP reforms in 1992. Therefore we estimated the long run equilibrium (LOP) relationships from Irish feed barley and wheat prices using Hansen’s (1992a) fully-modified single equation estimation methods and then tested for stability using his LC, MeanF and SupF tests. The LC and MeanF statistics test for a gradual shift in the parameters of cointegrating relationships, while the SupF statistic tests for a swift shift in the parameters of cointegrating relationships. The two estimated equilibrium relationships are 


$$
\begin{aligned}
p^{\text {wir }}= & -0.4611+0.001 t+1.0804 p^{\text {wuk }}+1.1086 e \\
& (1.21) \quad(4.85) \quad(14.48) \\
p^{\text {bir }}= & -1.2262+0.001 t+1.2330 p^{b u k}+1.1425 e
\end{aligned}
$$

where the fully modified t-statistics are in parenthesis. The p-values ${ }^{11}$ for the stability tests are presented in Table 4. It would appear that both cointegrating relationships are stable. We performed tests for cointegration using procedures from Engle and Granger (1987) and the residuals from the fully modified estimation procedure. The $\mathrm{p}$-values ${ }^{12}$ for these tests are also presented in Table 4 and suggest that (3) and (4) are cointegrating relationships. Thus the VEC model assumption in Section 2 seems justified. The two estimated equations seem to conform well with the LOP. The coefficients on the British price and the exchange rate are close to unity as expected and t-test statistics (based on the fully modified standard errors) that the coefficients are unity cannot be rejected at the $5 \%$ level.

We estimated each of the dynamic equations in (1) by ordinary least squares assuming a constant error variance. The $m_{i}$ in (1) are determined by using a combination of minimizing Bayesian Information Criterion (BIC) and ensuring that the residuals are white noise. For both equations in (1) the most parsimonious model resulted including the error correction term, the current monthly change in the British grain (barley or wheat) price, the current monthly change in the punt/sterling exchange rate and a $12^{\text {th }}$ lag in the monthly change in the MCA adjusted Irish grain (barley or wheat) price. The final equations were estimated by ordinary least squares and the residuals tested for first and twelfth order serial correlation, for first and twelfth order ARCH errors and residual normality using standard LM-tests. The estimated coefficients and misspecification test statistics are presented in Table 5. The test results suggest that there is no remaining serial correlation in the residuals but there are ARCH errors. Hansen (1992b) test statistics for parameter stability in linear regressions with stationary variables are presented in columns 3 and 5 of Table 5 . They suggest that the slope 
parameters are stable but the estimated standard error of the regression is not. We view this as reinforcing the ARCH test results. The squared residuals from each estimated equation are plotted in Figure 3. The figure suggests that the assumption of time varying error variances is appropriate.

\subsection{The MVGARCH model}

In the light of the analysis presented in the last subsection adding the MVGARCH specification to the VEC model seems justified. The estimated parameters in (1)-(2) are presented in Table 6. The estimated coefficients on the lagged conditional covariance matrix, A, are insignificant while the estimated coefficients in B are highly significant. This suggests that short-run deviations from the long-run conditional covariance matrix, $\mathrm{C}^{\prime} \mathrm{C}$, are important. It also suggests that a multivariate ARCH specification might be more appropriate than the multivariate GARCH model. A re-examination of the ARCH tests on the estimated VEC models highlight the fact that while all ARCH tests up to order 12 are significant only the first lagged squared residual is statistically significant in the test regressions. More formally we tested whether the coefficients in A are all statistically insignificant using a likelihood ratio test. The p-value for the test is 0.98. Thus we re-estimated (1)-(2) assuming multivariate ARCH errors, i.e. we dropped the last term in (2). The results are also presented in Table 6.

We can use to model to study the effect of changes in British grain prices or the punt/sterling exchange rate on Irish grain prices, ceteris paribus. A 10\% increase in British feed wheat prices has an immediate impact of increasing Irish feed wheat prices by $4.1 \%$. Within 9 months the increase is fully transmitted. A 10\% increase in British feed barley prices has an immediate impact of increasing Irish feed wheat prices by $2.2 \%$. Within 14 months the increase is fully transmitted. A $10 \%$ increase in the exchange rate has the same 
immediate impact of increasing Irish feed wheat and barley prices by 5.6\%. However the increase is fully transmitted to feed wheat prices within 9 months and to feed barley prices within 12 months. The main reason for the faster adjustment of the Irish wheat price to changes in either British wheat prices or the exchange rate is due to the fact that there are larger imports of wheat than barley from Britain. While there is no official data on this fact we have strong anecdotal evidence from many leading technical and industry experts within the Irish grain sector.

Examining the main diagonal elements of the estimated matrix $\mathrm{B}$ suggest that the conditional variance for Irish feed wheat prices is much more persistent than that of Irish feed barley prices. The persistence of the variance of the Irish wheat price may again be related to the larger quantities of wheat product traded. The significant off-diagonal element suggests the importance of volatility spillovers from the wheat to barley markets (and vice versa). In Figures 4-6 we plot the total conditional variance of feed barley and wheat prices and their conditional covariance respectively. In each figure we also plot the long-run values. It is evident that there is considerable short-run volatility. These figures suggest that it was the period prior to 1993 that appears to be most volatile. Given that the volatility is conditional, a reason for the lower volatility post 1993 may be that the UK prices are a more accurate determinant of Irish prices than prior to 1993. In 1993 the currency issue was somewhat stabilised by the fact that post 1993 green rates were aligned on monetary rates, resulting in smaller monetary gaps and MCA's were removed. Whilst we include the relevant policy levers (MCA amounts) pre 1993, there often were lags between the fixing of green rates and market rate adjustments. This could result in greater volatility in the price transmission relationship between UK and Irish prices. However, the underlying hypothesis that prices post 1993 due to lower intervention prices are more volatile than pre 1993 obviously still holds in an unconditional sense. Most of the large peaks in the short run volatility of wheat 
and barley would seem to correspond to a significant agri-monetary development. On April 6 1986 there was realignment within the European Monetary System (EMS). In August 1992 for instance, the turmoil within European currencies resulted in the UK and Italy withdrawing from the Exchange Rate Mechanism (ERM). In August 1993 there was the unexpected development of all EC currencies except Sterling and the lira floating within a new 30 per cent band of the central rate. The punt was no longer fixed against the Ecu. All of these currency changes prompted significant volatility in the Irish grain market.

\subsection{Forecasting condition first and second moments of Irish grain prices}

In Ireland, specialist grain producers typically harvest in August-October and plant in October. At the time of deciding how to allocate farmland between barley and wheat farmers care about the mean, variance and covariances of the expected returns (defined the logarithm of revenue per ton minus the logarithm of cost per ton) from barley and wheat one-year ahead at the time of harvest during the following August/September. Total return would include price, yield/output and cost uncertainty. However, as in Coyle (1992), Saha (1997) and Oude Lansink (1999), we assume that yields and costs per ton are non-stochastic and known in advance by producers. Thus the uncertainty in return per ton is due to uncertainty in the grain price per ton one-year ahead. Many of the production models under price uncertainty that were mentioned in Section 2 use the specification as outlined by Chavas and Holt (1990) to forecast the conditional means, variances and covariances of commodity prices. All of these studies use annual data. Using monthly observations the Chavas and Holt (1990) specification for one-year ahead forecasts is given by

$$
\begin{gathered}
p_{t}=\alpha_{0}+\alpha_{1} p_{t-12}+u_{t} \quad u_{t} \sim \operatorname{NIID}\left(0, \sigma_{u}^{2}\right) \\
\operatorname{var}_{t}\left(p_{t}\right)=0.50\left(\hat{u}_{t-12}^{2}\right)+0.33\left(\hat{u}_{t-24}^{2}\right)+0.17\left(\hat{u}_{t-36}^{2}\right) \\
\operatorname{cov}_{t}\left(p_{t}^{i} p_{t}^{j}\right)=0.50\left(\hat{u}_{t-12}^{i} \hat{u}_{t-12}^{j}\right)+0.33\left(\hat{u}_{t-24}^{i} \hat{u}_{t-24}^{j}\right)+0.17\left(\hat{u}_{t-36}^{i} \hat{u}_{t-36}^{j}\right)
\end{gathered}
$$


where $p$ is the price (or some studies the return) of the series of interest and $\hat{u}_{t}$ is estimated from (5). There are a few major issues with this specification. The process for the conditional mean is very simple and is not suitable for modeling grain prices in a small open economy like Ireland. The weights $(0.5,0.33$, and 0.17$)$ on the lag structure in (6) and (7), and the lag lengths are both arbitrary choices of the researcher i.e. they are impositions by the researcher on the expectation mechanism of producers governing the variances/covariances of the competing output prices.

In order to compare one-year ahead forecasts of the VEC-MVGARCH model with (5)-(7) we need to modify equations (1)-(2) to account for the information structure. For forecasting purposes the VEC model can be written in its linear autoregressive distributed lag form as

$$
\begin{aligned}
& p_{t}^{w i r}=f\left(1, t, p_{t-12}^{w i r}, p_{t-13}^{w i r}, p_{t-12}^{w u k}, p_{t-13}^{w u k}, e_{t-12}, e_{t-13}, u_{t}^{w}\right) \\
& p_{t}^{b i r}=f\left(1, t, p_{t-12}^{b i r}, p_{t-13}^{b i r}, p_{t-12}^{b u k}, p_{t-13}^{b u k}, e_{t-12}, e_{t-13}, u_{t}^{b}\right) \\
& {\left[\begin{array}{c}
u_{t}^{w} \\
u_{t}^{b}
\end{array}\right]=\left[\mathbf{u}_{t}\right] \sim \operatorname{MN}\left(0, \mathbf{H}_{t}\right)}
\end{aligned}
$$

and the conditional covariance matrix, $\mathbf{H}_{t}$, is given by

$$
\mathbf{H}_{t}=\mathbf{C}^{\prime} \mathbf{C}+\mathbf{B}^{\prime}\left(\mathbf{u}_{t-12} \mathbf{u}_{t-12}^{\prime}\right) \mathbf{B}
$$

We start estimating these models using data up to September 1989 and then forecast Irish barley and wheat prices, their conditional variances and the conditional covariance for the following September. Then, we add one year's data and repeat the forecasting exercise. This produces eleven September forecasts over the 1990-2000 period for the five series of interest. We use two commonly used loss functions to evaluate the forecasts; the mean squared error (MSE) and the mean absolute deviation (MAD). It is easy to calculate the MSE and MAD for the mean price forecasts as we have data on the actual price of barley and wheat the following September. In order to evaluate the forecasts of the conditional second moments we follow Hansen and Lunde (2001). They suggest that realized volatility in the intervening 
time period could be used as an actual measure of volatility ${ }^{13}$. We calculate the variance and covariance of grain prices using the intervening twelve months and compare these to the estimated conditional forecasts.

The MSE and MAD criterion are presented in Table 7. Our suggested model produces forecasts with lower loss functions than forecasts made using the Chavas and Holt (1990) methodology. In order to test whether the difference is significant we use a recently developed test of superior predictive ability (see Hansen (2001) for a thorough discussion) ${ }^{14}$. Critical values are generated using bootstrap methods. The SPA tests for the best standardized forecasting performance relative to the benchmark model. The null hypothesis is that none of the competing models is better than the benchmark. We define the Chavas and Holt (1990) model as the benchmark. The p-values for the SPA tests are presented in Table 7 and indicate that the VEC-MVGARCH produces superior forecasts at the $5 \%$ significance level in some cases and at the $10 \%$ significance level in nearly all the cases. This result does not depend on whether loss functions using either mean squared error or mean absolute deviations are employed.

\section{Conclusion}

This paper has sought primarily to address the question of international price transmission between Irish and UK feed grains within an increasingly volatile climate for commodity prices. The traditional model of price transmission (VEC) has been expanded in this case to allow for time varying conditional variances and covariances amongst the Irish price series modelled. Standard LM-tests failed to reject the hypothesis of ARCH errors in the standard VEC framework. Therefore allowing for multivariate ARCH errors improves the efficiency of the estimated parameter results. Interestingly, the period of most significant volatility appears to have been prior to 1993 and not subsequently as had originally been hypothesized. 
As this volatility is conditional, this result may have been due to trade distortions owing to the differences, which occurred between green and market exchange rates. From 1993 on, green rates were aligned on the market rate thereby removing this potential for distortion and permitting UK grain prices to more accurately capture movements in equivalent Irish prices.

The modeling of variances and covariances of price series is also an important development particularly in the context of the increased role played by uncertainty in producer's decision-making processes. Increasing numbers of international studies are including expressions for the variances and covariances of prices as motivated by second moments uncertainty models. To date, many of these moments forecasts have been generated by use of the Chavas and Holt (1990) methodology where the relative effects of past variances and covariances on producer decision making are assumed by the researcher. Through use of the MVGARCH component of the model estimated in this paper, these relative effects are determined entirely by the data. The forecasts from the VEC-MVGARCH model are then compared with those achieved with the Chavas and Holt methodology using approaches devised by Hansen and Lunde (2001) and Hansen (2001). The forecasts achieved with the VEC-MVGARCH approach outperform those of the Chavas and Holt (1990) approach in all cases at the $10 \%$ level and in most cases at the $5 \%$ level.

\section{Data Appendix}

The Irish prices and exchange rates were obtained from monthly bulletins of the Irish Cereals Authority (CAI) whilst the UK prices were obtained from the UK's Home Grown Cereals Authority (HGCA). Monetary compensation amounts (MCAs) were introduced to compensate producers for unfavorable changes in their country's green rates. These amounts were applied at a country's frontier where they acted as a tax on exports from countries where farm prices were being kept low and a subsidy on those where prices were being kept high. 
The MCAs were to be phased out by gradually aligning the green rates on the market exchange rates. The application of the MCA system at the internal frontiers of the Community was incompatible with the introduction of the Single Market on the 1 January 1993. With the introduction of the Single Market, green rates were aligned on monetary rates, which resulted in only small monetary gaps. Thus MCAs were removed. The relevant MCA amounts were again obtained from the CAI’s monthly bulletins.

\section{References}

Ardeni, P.G. (1989). Does the law of one price really hold for commodity prices? American Journal of Agricultural Economics 71: 661-69.

Baba, Y., Engle R.F., Kraft D.F. and Kroner K.F. (1991). Multivariate simultaneous generalized ARCH, Department of Economics, University of California, San Diego, unpublished manuscript

Boyle, G.E. and McQuinn, K. (2001). Production decisions under price uncertainty for Irish wheat and barley producers in Agricultural Sector Modelling and Policy Information Systems, Wissenschaftsverlag Vauk Kiel KG. Ed.s T. Heckelei and H.P. Witzke and W. Henrichsmeyer, 135-143.

Chavas, J.B. and Holt M.T. (1990). Acreage decisions under risk: The case of corn and soybeans. American Journal of Agricultural Economics 72: 529-38.

Coyle, B. (1992). Risk aversion and price risk in duality models of production: A linear mean-variance approach. American Journal of Agricultural Economics 74: 849-59.

Coyle, B. (1999). Risk aversion and yield uncertainty in duality models of production: A mean-variance approach\}. American Journal of Agricultural Economics 81: 553-67.

Crain S.J. and Lee J.H. (1996). Volatility in wheat spot and futures markets 1950-1993: Government farm programs, seasonality, and causality, Journal of Finance 51: 325-43. 
Dawson, P.J., Tiffin A.L. and B. White (2000). Optimal Hedging Ratios for Wheat and Barley at the LIFFE: A GARCH Approach. Journal of Agricultural Economics 51: 147-161. Diakosavvas D. (1995). How integrated are world beef markets? The case of Australian and U.S. beef markets, Agricultural Economics 12: 37-53.

Dickey, D. and Fuller W. (1981). Likelihood ratio statistics for autoregressive time series with a unit root. Econometrica 9: 1057-1172.

Elliott, G., Rothenberg, T.J. and Stock, J.H. (1996). Efficient tests for an autoregressive unit root. Econometrica 64: 813-836.

Engle, R.E. and Granger C.W.J. (1987). Cointegration and Error-Correction: Representation, Estimation, and Testing. Econometrica 55: 251-276.

Flavin, T.J. and Wickens, M.R. (2001). Macroeconomic influences on optimal asset allocation. Economics Department, Working Paper Series N108/03/01, NUI Maynooth, Ireland.

Franses, P.H. (1998). Time series models for business and economic forecasting, Cambridge University Press: Cambridge.

Franses, P.H. and Hobijn B. (1997). Critical values for unit root tests in seasonal time series. Journal of Applied Statistics 24: 25-47.

Ghoshray A., Lloyd T.A. and Rayner A.J. (2000). EU wheat prices and its relation with other major wheat export prices, Discussion paper No.00/8, University of Nottingham

Goodwin B.K. and T.C. Schroeder (1991). Cointegration tests and spatial price linkages in regional cattle markets, American Journal of Agricultural Economics 72: 682-93.

Haigh M.S. and H.L. Bryant. (2001). The effect of barge and ocean freight prices volatility in international grain markets. Agricultural Economics 25: 41-58.

Hansen, B.E. (1992a). Testing for parameter instability in regressions with I(1) processes. Journal of Business and Economic Statistics 10: 321-335. 
Hansen, B.E. (1992b). Testing for parameter instability. Journal of Policy Modelling 14: 517533.

Hansen, P.R. and Lunde, A. (2001). A forecast comparison of volatility models: does anything beat a GARCH(1,1)? Department of Economics, Working Paper No. 01-04, Brown University.

Hansen, P.R. (2001). An unbiased and powerful test for superior predictive ability. Manuscript, Department of Economics, Brown University.

Holt, M. and Aradhyula S. (1990). Price risk in supply equations: an application of GARCH time-series models to the U.S. broiler market. Southern Economic Journal 57: 230-42.

Holt, M. (1993). Risk response in the beef marketing channel: a multivariate generalized ARCH-M approach. American Journal of Agricultural Economics 75: 559-571.

Hylleberg, S., Engle, R.F., Granger C.W.J. and Yoo, B.S. (1990). Seasonal integration and cointegration. Journal of Econometrics 44: 215-238.

Jumah, A. and Kunst, R.M. (2001). The effects of dollar/sterling exchange rate volatility on futures markets for coffee and cocoa. European Review of Agricultural Economics 28: 307328.

Loy, J.P. and Weaver R. (1998). Inflation and relative price volatilities in Russian food markets. European Review of Agricultural Economics 25: 373-394.

MacKinnon, J.G. (1994). Approximate asymptotic distribution functions for unit-root and cointegration tests. Journal of Business and Economic Statistics 12: 167-176.

Maddala G.S. and Kim I. M. (1998). Unit roots, cointegration and structural change. Cambridge: Cambridge University Press

Management Data for Farm Planning, Teagasc - selected years publications.

McKenzie, A.M. and Holt M. (1998). Market efficiency in agricultural futures markets. Paper to the 1998 American Agricultural Economics Association Annual Meeting in Salt Lake City. 
Mohanty S. and E. Wesley E., Petersen F. and N.C. Kruse (1995). Price asymmetry in the international wheat market, Canadian Journal of Agricultural Economics 43: 355-66.

Mohanty S. and E. Wesley E., Petersen F. and D.B. Smith (1996). Relationships between U.S. and Canadian wheat prices, Canadian Journal of Agricultural Economics 44: 365-76.

Natcher W.C. and Weaver R.D. (1999). The transmission of price volatility in the beef markets: A multivariate approach. Paper presented to the American Agricultural Economics Association Annual Meeting, Nashville Tennessee.

Oude Lansink A. (1999). Area allocation under price uncertainty on Dutch arable farms, Journal of Agricultural Economics 50: 93-105.

Pantula, S.G., Gonzalez-Farias, G. and Fuller W.A. (1994). A comparison of unit-root test criteria. Oxford Bulletin of Economics and Statistics 12: 449-459.

Perron, P. (1997). Further evidence on breaking trend functions in macroeconomic variables. Journal of Econometrics 80: 355-385.

Saha, A. (1997). Risk preference estimation in the nonlinear mean standard deviation approach. Economic Inquiry 35: 61-71.

Weaver R.D. and Natcher, W.C. (2000). Commodity price volatility under new market orientations, Paper presented at the Agricultural Economics Society Annual Meeting, Manchester, UK.

Yang, S.R. and Brorsen B.W. (1992). Nonlinear dynamics of daily cash prices. American Journal of Agricultural Economics ??: 706-715.

Zivot, E. and Andrews D.W.K. (1992). Further evidence on the great crash, the oil-price shock, and the unit-root hypothesis. Journal of Business and Economic Statistics 10: 251-70. 
Table 1. Cereals supply balance

\begin{tabular}{|c|c|c|c|}
\hline Year & Usable Production & Domestic Use & Self-Sufficiency \\
\hline & \multicolumn{2}{|c|}{000 tonnes } & $\%$ \\
\hline 1997-1998 & 1,964 & 2,204 & 88 \\
\hline 1998-1999 & 1,865 & 2,285 & 82 \\
\hline $1999-2000$ & 2,011 & 2,545 & 79 \\
\hline
\end{tabular}

Source: The Irish Central Statistics Office (CSO) 2002. 
Table 2. Basic statistics for annual growth rates in wheat and barley prices

\begin{tabular}{|c|c|c|c|}
\hline Mean & 1982:01-1992:12 & 1993:01-2001:03 & 1982:01-2001:03 \\
\hline Irish Wheat Price & 2.15 & -5.84 & -1.46 \\
\hline British Wheat Price & 0.74 & -7.09 & -2.80 \\
\hline Irish Barley Price & 2.61 & -5.90 & -1.24 \\
\hline British Barley Price & 0.77 & -6.05 & -2.31 \\
\hline \multicolumn{4}{|l|}{ Standard Deviation } \\
\hline Irish Wheat Price & 9.24 & 12.68 & 11.61 \\
\hline British Wheat Price & 7.59 & 13.30 & 11.23 \\
\hline Irish Barley Price & 9.50 & 12.41 & 11.68 \\
\hline British Barley Price & 6.01 & 13.24 & 10.50 \\
\hline
\end{tabular}


Table 3. Unit root tests for wheat and barley prices and the sterling/punt exchange rate

\begin{tabular}{lccccc}
\hline & $\begin{array}{c}\text { Irish Wheat } \\
\text { Price }\end{array}$ & $\begin{array}{c}\text { Irish Barley } \\
\text { Price }\end{array}$ & $\begin{array}{c}\text { UK Wheat } \\
\text { Price }\end{array}$ & $\begin{array}{c}\text { UK Barley } \\
\text { Price }\end{array}$ & $\begin{array}{c}\text { Exchange } \\
\text { Rate }\end{array}$ \\
\cline { 2 - 6 } Non-seasonal & & & & & \\
ADF & -1.73 & -2.03 & -1.51 & -1.41 & -1.17 \\
ADF-GLS & -2.58 & -3.09 & -1.76 & -1.61 & -2.13 \\
Wtd. Sym. & -2.65 & -3.25 & -1.61 & -1.52 & -1.95 \\
Franses $\pi_{1}$ & -2.56 & -3.00 & -0.78 & -0.59 & -1.49 \\
Breaking trend & & & & & \\
Zivot-Andrews A & -4.32 & $-5.17^{\mathrm{a}}$ & -4.34 & -4.29 & -3.32 \\
Zivot-Andrews B & -4.24 & -3.80 & -4.05 & -4.35 & \\
Zivot-Andrews C & $-4.88^{\mathrm{a}}$ & $-5.40^{\mathrm{a}}$ & -4.46 & -4.46 & \\
Perron A & $-4.32^{\mathrm{c}}$ & $-5.14^{\mathrm{a}, \mathrm{c}}$ & $-4.34^{\mathrm{c}}$ & $-4.29^{\mathrm{c}}$ & $-3.32^{\mathrm{c}}$ \\
Perron B & -4.23 & -3.76 & -4.05 & -4.35 & \\
Perron C & $-4.89^{\mathrm{a}, \mathrm{c}}$ & $-5.37^{\mathrm{a}, \mathrm{c}}$ & $-4.46^{\mathrm{c}}$ & $-4.46^{\mathrm{c}}$ & \\
Seasonal & & & & & \\
Franses $\pi_{2}$ & $-4.96^{\mathrm{b}}$ & $-3.69^{\mathrm{b}}$ & -2.67 & -2.87 & $-3.71^{\mathrm{b}}$ \\
Franses $\pi_{3}-\pi_{12}$ & $72.53^{\mathrm{b}}$ & $10.43^{\mathrm{b}}$ & $9.03^{\mathrm{b}}$ & $9.29^{\mathrm{b}}$ & $6.94^{\mathrm{b}}$ \\
\hline
\end{tabular}

Note: British wheat and barley prices are obtained from HGCA. Irish wheat and barley prices are obtained from the CAI. The Irish prices are adjusted for monetary compensatory amounts and quoted in punts. A constant and trend were included in the test regressions for the price series. A constant was included in the test regressions for the exchange rate series. In all of the unit root tests appropriate lag lengths on the adjustment parameters are chosen by reduction methods using a $10 \%$ level of significance.

a denotes significance at the $5 \%$ level.

b denotes significance at the $1 \%$ level.

c coefficient on the pulse dummy variable in the Perron (1997) tests is insignificant at the $1 \%$ level.

ADF is an augmented Dickey-Fuller unit root test.

ADF-GLS is a unit root test from Elliot, Rothenberg and Stock (1996).

Wtd. Sym is a weighted symmetric unit root test from Pantula, Gonzalez-Farias and Fuller (1994).

Franses $\pi_{1}$ is a non-seasonal unit root test from Franses (1998).

The Zivot and Andrews (1992) tests A, B and C are tests of the unit root null hypothesis versus alternatives of breaking intercept, breaking slope and breaking intercept and slope respectively.

The Perron (1997) tests A, B and C are tests of the unit root with a single break null hypothesis versus alternatives of breaking intercept, breaking slope and breaking intercept and slope respectively.

Franses $\pi_{2}$ and $\pi_{3}-\pi_{12}$ are non-seasonal unit root tests from Franses (1998). 
Hansen (1992a) - LC Cointegrating Regression

Cointegrating Regression

Hansen (1992a) - MeanF

0.08

0.13

Hansen (1992a) - SupF

0.15

0.20

Engle-Granger (1987)

0.20

Note: The Hansen (1992a) tests are for parameter stability based on the fully modified estimated cointegrating regression. The LC and MeanF test for a gradual change in the coefficients and the SupF tests for a swift change. The appropriate p-values are obtained from Hansen (1992a). The Engle-Granger (1987) cointegration tests are based on the residuals of fully modified estimated cointegrating regression. The appropriate p-values are obtained from MacKinnon (1994). 
Table 5. OLS parameter estimates of the vector error correction model

\begin{tabular}{lcccc}
\hline & Wheat Prices & Hansen Test & Barley Prices & Hansen Test \\
ECT & -0.32 & 0.22 & -0.20 & 0.71 \\
$\Delta \mathrm{p}^{\text {wir }}(-12)$ & $(6.21)$ & & $(4.92)$ & \\
& 0.22 & 0.14 & & \\
$\Delta \mathrm{p}^{\text {wuk }}$ & $(4.15)$ & & & \\
& 0.44 & 0.05 & & 0.04 \\
$\Delta \mathrm{p}^{\text {bir }}(-12)$ & $(7.18)$ & & & \\
$\mathrm{s}^{\text {buk }}$ & & & 0.37 & 0.23 \\
& & & $0.88)$ & 0.21 \\
$\Delta \mathrm{e}$ & & & 0.32 & \\
& 0.56 & 0.09 & 0.59 & \\
$\hat{\sigma}$ & $(4.08)$ & & $(4.63)$ & \\
AR(1) & $3.88 \%$ & 0.59 & $3.62 \%$ & \\
AR(12) & 0.28 & & 0.33 & \\
ARCH(1) & 0.31 & & 0.23 & \\
ARCH(12) & 0.00 & & 0.00 & \\
Normality & 0.00 & & 0.00 & \\
\hline
\end{tabular}

Note: Absolute t-statistics are in parenthesis. ECT is the error correction term.

P-Values are presented for serial correlation, ARCH and normality tests.

The Hansen (1992b) test statistics are for parameter stability in linear regressions with stationary variables are presented in columns 3 and 5 . The $5 \%$ critical value is 0.470 and the $1 \%$ critical value is 0.748 
Table 6. Maximum likelihood parameter estimates of the multivariate GARCH/ARCH models

\begin{tabular}{|c|c|c|c|c|}
\hline & & & & \\
\hline & GARCH & ARCH & GARCH & $\mathrm{ARCH}$ \\
\hline ECT & -0.26 & -0.25 & -0.17 & -0.16 \\
\hline & (7.83) & (7.68) & (5.64) & (5.39) \\
\hline$\Delta \mathrm{p}^{\mathrm{wir}}(-12)$ & 0.21 & 0.20 & & \\
\hline & (5.14) & (4.93) & & \\
\hline$\Delta p^{\text {wuk }}$ & 0.42 & 0.41 & & \\
\hline & (12.15) & (12.28) & & \\
\hline$\Delta \mathrm{p}^{\mathrm{bir}}(-12)$ & & & 0.30 & 0.29 \\
\hline & & & (5.65) & (5.57) \\
\hline$\Delta p^{\text {buk }}$ & & & 0.22 & 0.22 \\
\hline & & & (4.87) & $(4.87)$ \\
\hline$\Delta \mathrm{e}$ & 0.56 & 0.56 & 0.57 & 0.56 \\
\hline & (5.73) & (5.58) & (4.78) & $(4.91)$ \\
\hline
\end{tabular}

Note: Absolute t-statistics are in parenthesis. ECT is the error correction term.

Multivariate GARCH model

$$
\hat{\mathbf{A}}=\left[\begin{array}{ll}
0.0005 & \\
(0.000) & \\
-0.0005 & -0.01739 \\
(0.000) & (0.000)
\end{array}\right] \quad \hat{\mathbf{B}}=\left[\begin{array}{ll}
0.71 & \\
(8.92) & \\
-0.25 & 0.13 \\
(4.59) & (1.89)
\end{array}\right] \quad \hat{\mathbf{C}}=\left[\begin{array}{ll}
3.76 & \\
(5.35) & \\
1.76 & 3.71 \\
(3.98) & (18.70)
\end{array}\right]
$$

Multivariate ARCH model

$$
\hat{\mathbf{B}}=\left[\begin{array}{ll}
0.68 & \\
(8.71) & \\
-0.26 & 0.16 \\
(4.83) & (2.43)
\end{array}\right] \quad \hat{\mathbf{C}}=\left[\begin{array}{ll}
3.61 & \\
(6.07) & \\
1.83 & 3.71 \\
(5.02) & (18.88)
\end{array}\right]
$$


Table 7. Forecast evaluation

\begin{tabular}{lcccc}
\hline Loss function & \multicolumn{2}{c}{ MAD } & \multicolumn{2}{c}{ MSE } \\
Model & Chavas and HoltMVGARCHChavas and HoltMVGARCH \\
Price of wheat & .10351 & .09031 & .01585 & .01358 \\
Price of barley & .09486 & .08900 & .01416 & .01222 \\
Condition variance of the price of wheat & .00909 & .00472 & .00016 & .00003 \\
Condition variance of the price of barley & .00863 & .00412 & .00014 & .00002 \\
Condition covariance & .00881 & .00436 & .00014 & .00002 \\
All series & .04498 & .03850 & .00609 & .00517 \\
& & & & \\
Hansen's (2001) SPA test - pvalues & MAD & MSE & \\
Price of wheat & .053 & .028 & \\
Price of barley & .272 & .117 & \\
Condition variance of the price of wheat & .050 & .067 & \\
Condition variance of the price of barley & .027 & .048 & & \\
Condition covariance & .045 & .061 & & \\
All series & .015 & .029 & & \\
\hline
\end{tabular}

Note: The forecasts from using the Chavas and Holt (1990) methodology were defined as the benchmark model in the Hansen (2001) SPA test. 


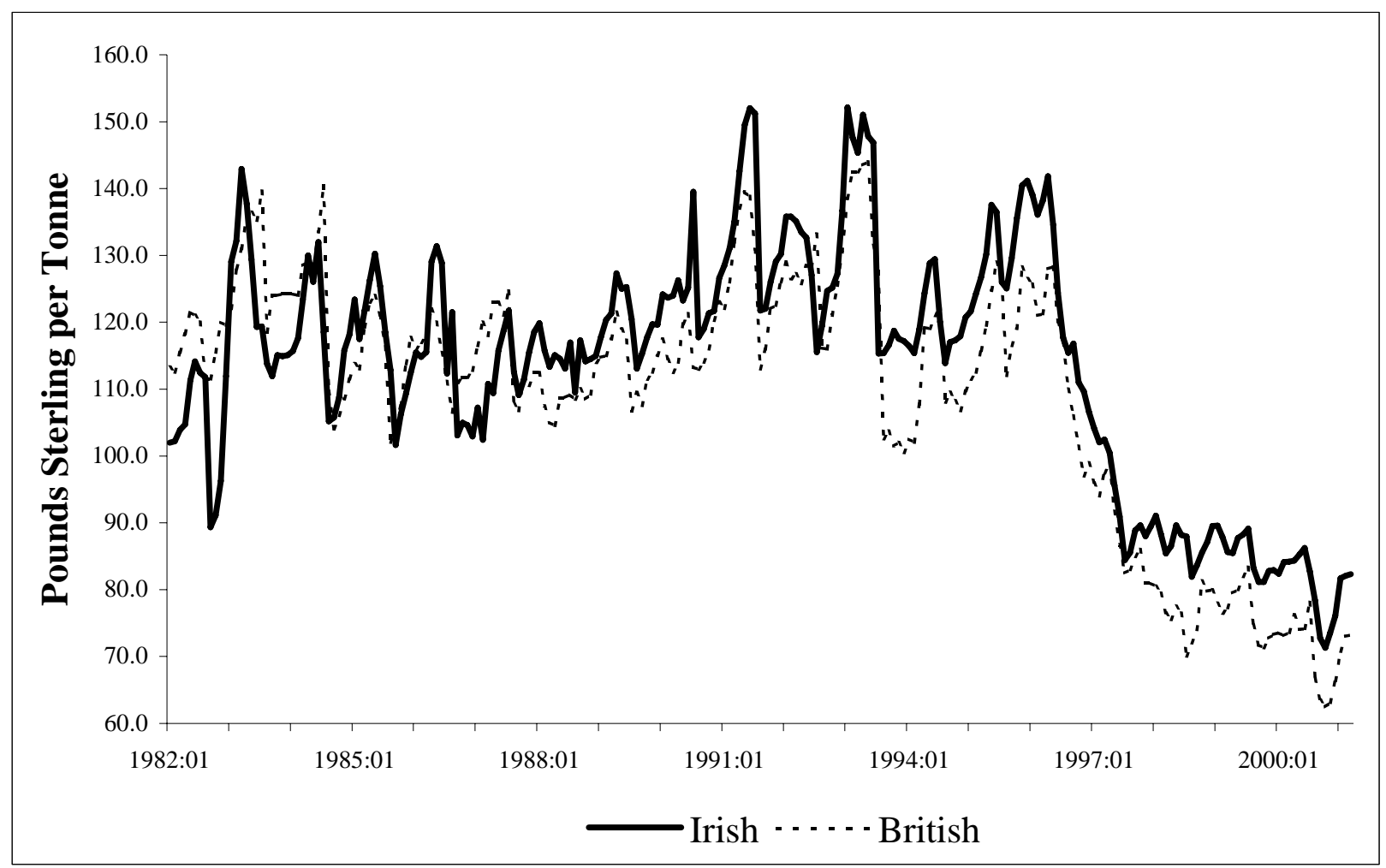

Figure 1. Irish and British feed wheat prices in pounds sterling. 


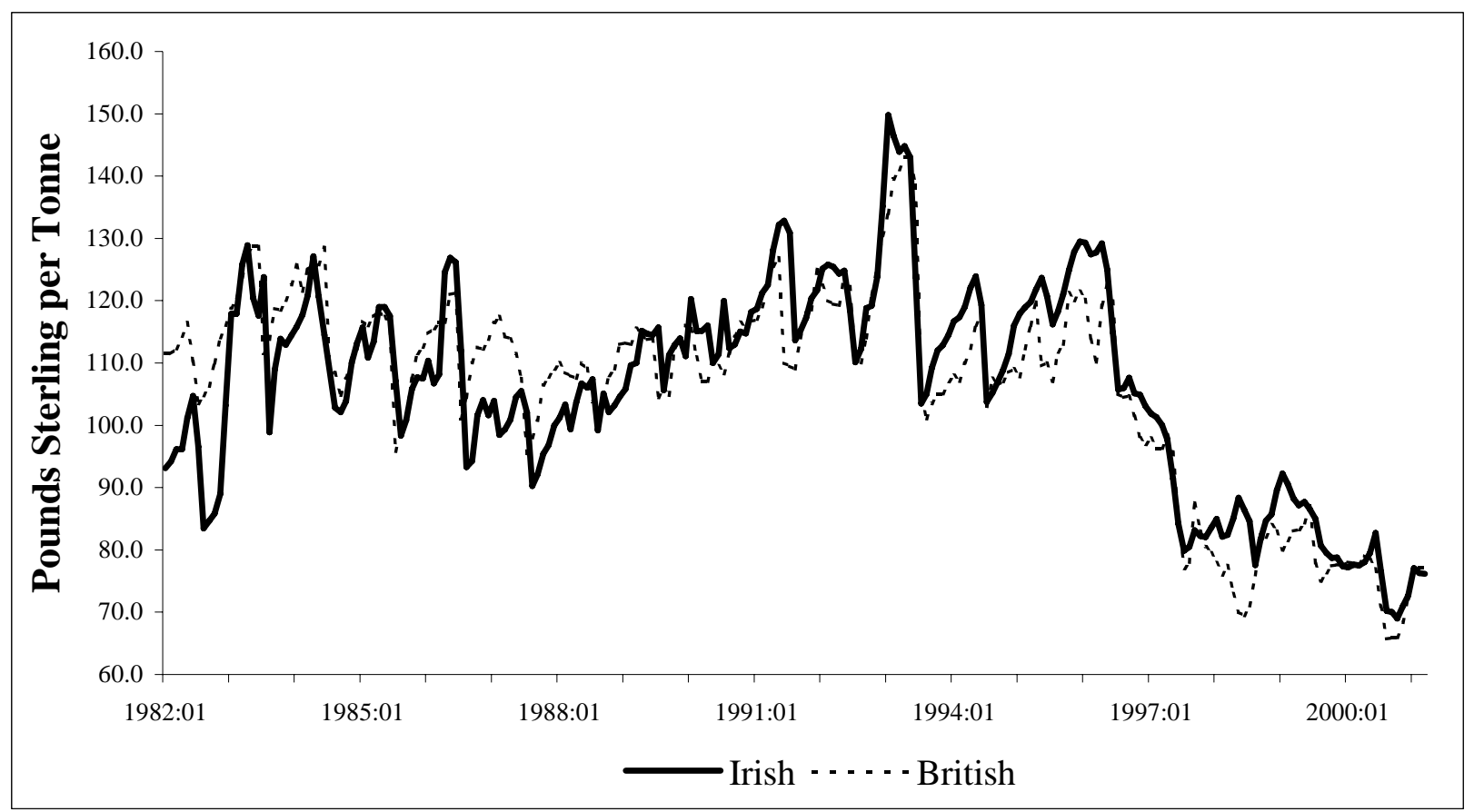

Figure 2. Irish and British feed barley prices in pounds sterling. 


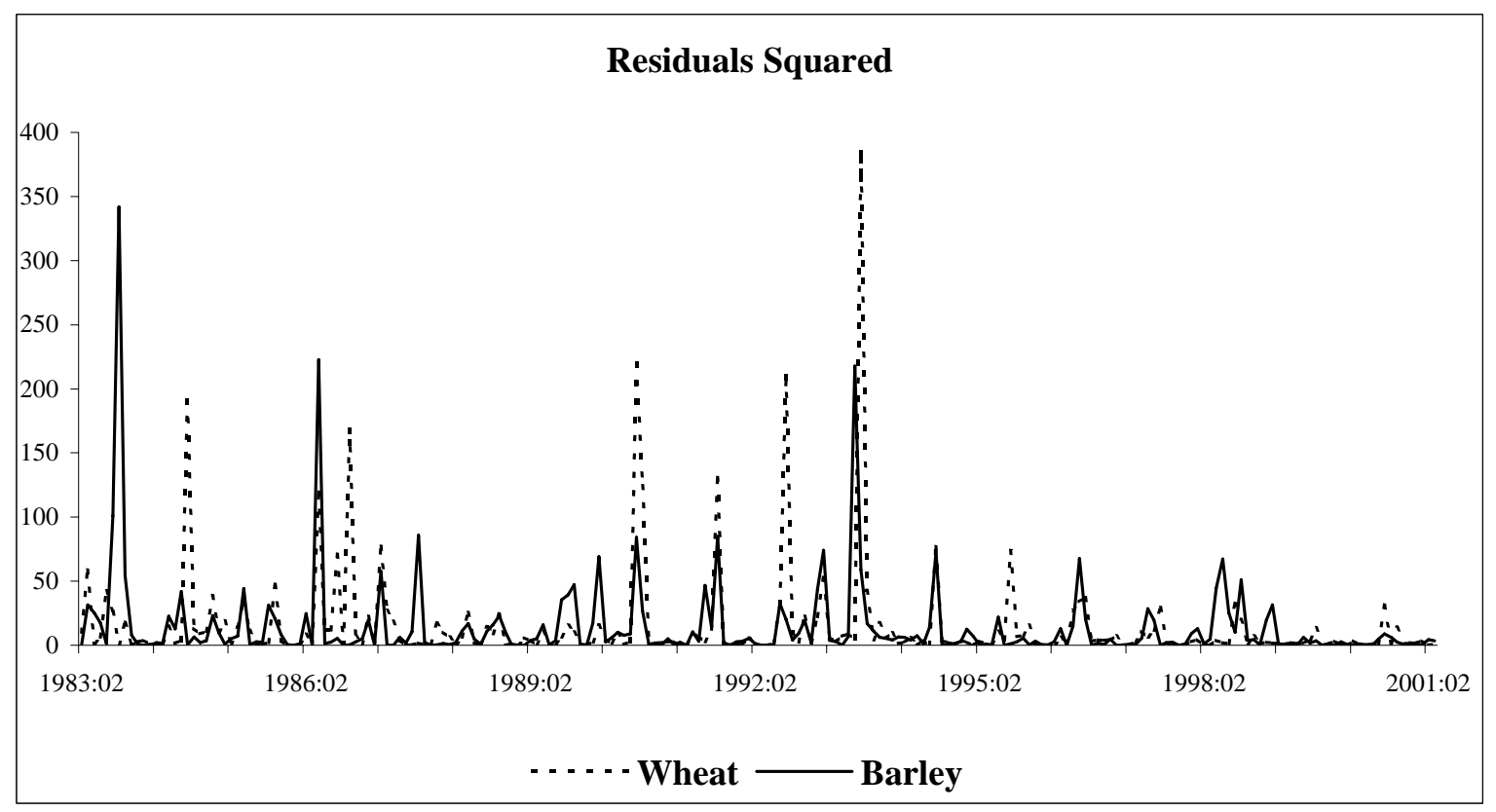

Figure 3. The squared residuals from the VEC model. 


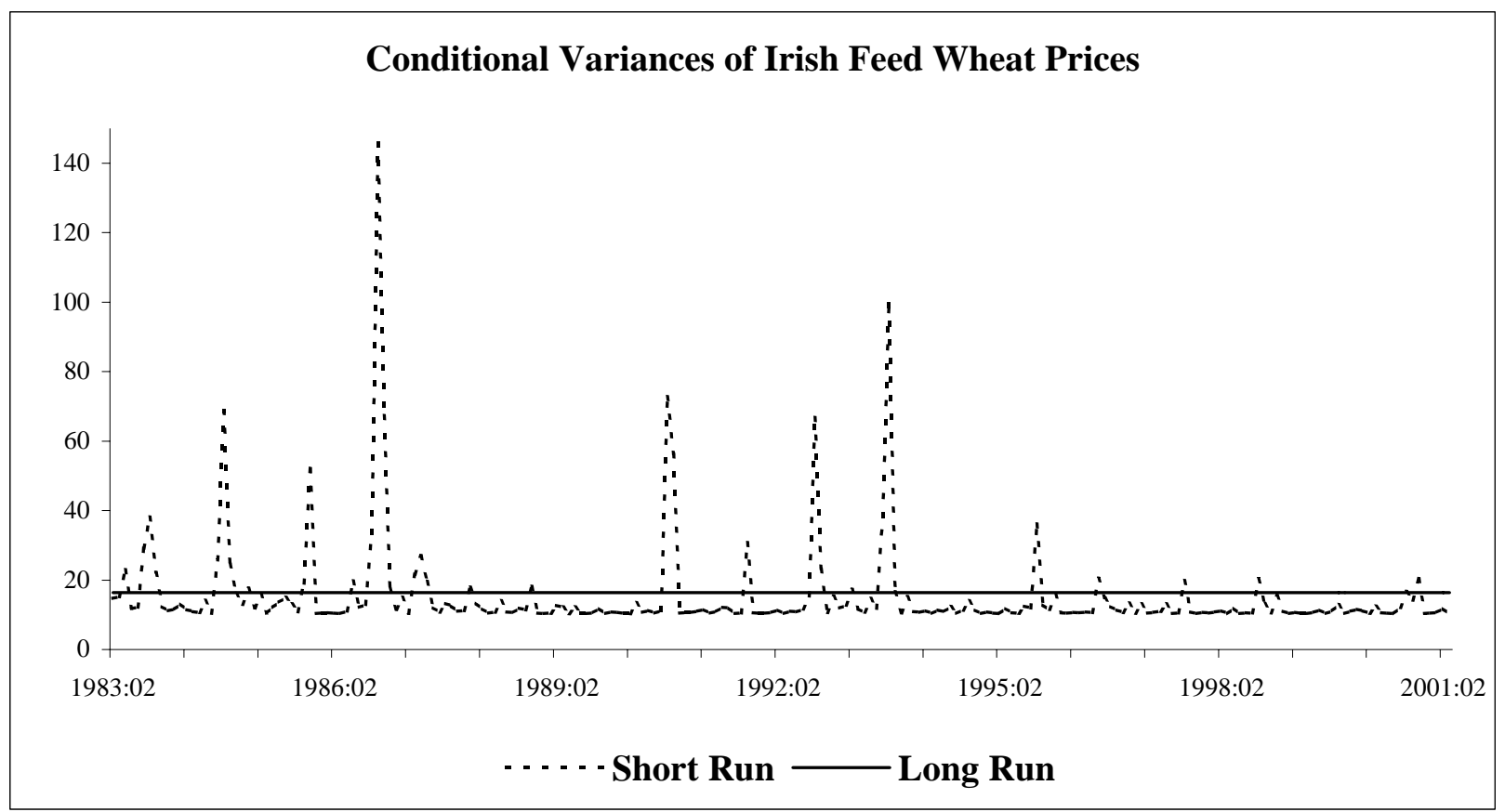

Figure 4. The short and long run conditional variance of Irish feed wheat. 


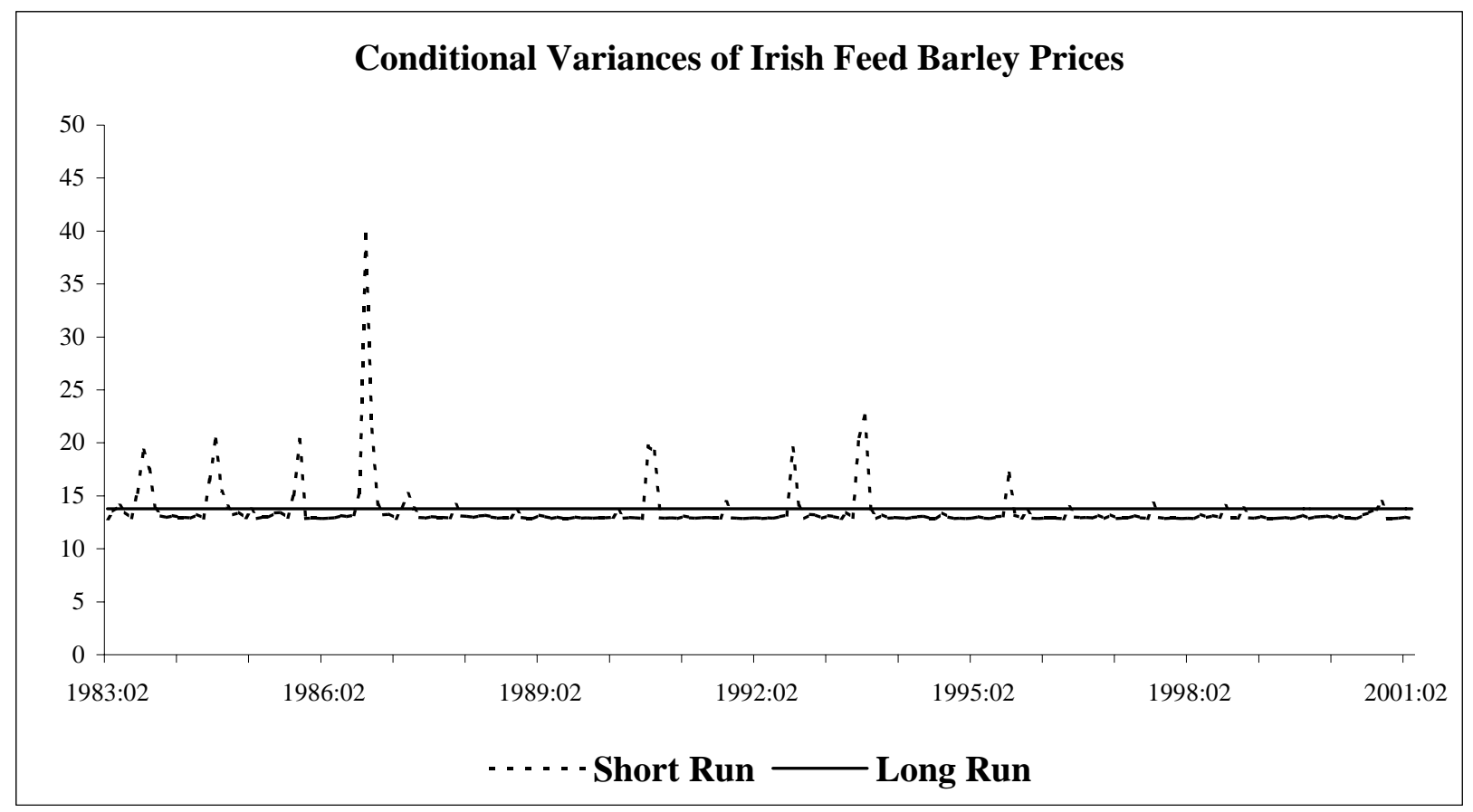

Figure 5. The short and long run conditional variance of Irish feed barley. 


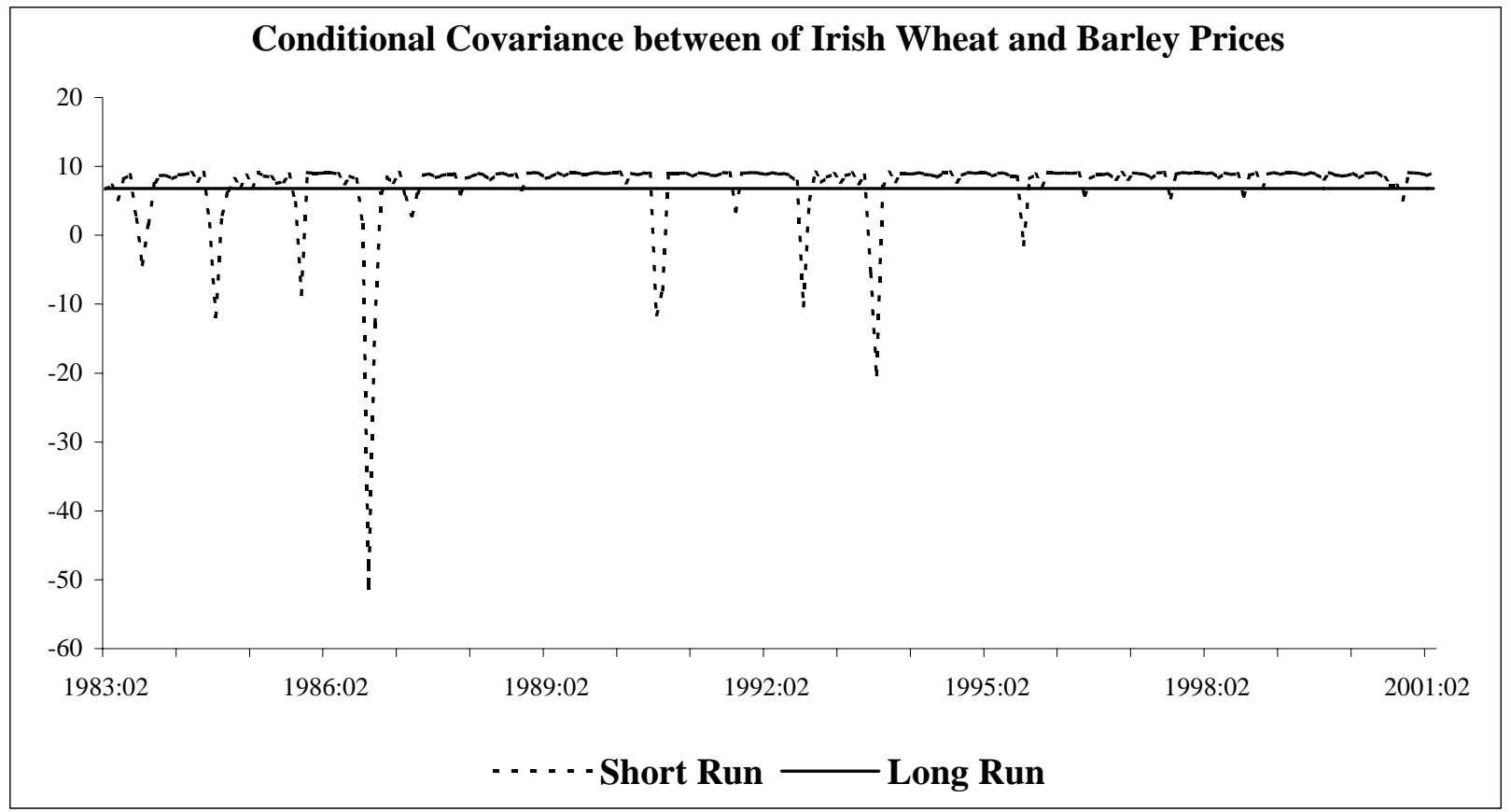

Figure 6. The short and long run conditional covariance between Irish feed wheat and barley. 


\section{Endnotes}

${ }^{1}$ The most recent set of projections for internal EU prices by the Food and Agricultural Policy Research Institute (FAPRI) at the University of Missouri illustrate the degree to which internal EU grain prices are converging with equivalent world prices for the 2001-2010 time period.

More information on FAPRI-Missouri is available online at http://www.fapri.missouri.edu/.

${ }^{2}$ These reforms also saw the introduction of direct aid payments for the arable sector. The overall effect of the two EU reforms on the variability of total producer income is somewhat complicated by the introduction and subsequent increase in the levels of compensatory payments paid out to producers. As the producer need only plant the cereal in order to claim these payments, the amount received is impervious to either price or yield uncertainty and as such constitutes a relatively "riskless" component of overall producer income. However one can argue that as these compensation payments are the same across all grains, the level and variability of the market return will be of increased importance in the planting decision made.

${ }^{3}$ Self-sufficiency ratio $=$ Production/ Domestic Use

${ }^{4}$ Cereals Association of Ireland (CAI) Monthly Market Intelligence Bulletin and USDA Attaché Reports.

${ }^{5}$ A series of workshops established for the purposes of the FAPRI-Ireland grains model attended by many leading technical and industry experts within the Irish grain sector provided very strong anecdotal evidence for such a specification. For more information on the FAPRI-Ireland partnership see http://www.tnet.teagasc.ie/fapri/usefulinks.htm

${ }^{6}$ In particular, market exchange rates and Monetary Compensation Amounts (MCA) were available on a monthly basis for trade between Ireland and the UK.

${ }^{7}$ Loy and Weaver (1998) being a notable exception.

${ }^{8}$ Corn, pork bellies, soybean, soybean meal, soybean oil, sugar and wheat.

${ }^{9}$ The number of lags in all of the unit root tests is determined by a t-statistic greater than 1.64 on the last coefficient on the lagged changes of the series in the test regression.

${ }^{10}$ Applying a similar unit root testing procedure to the first differences of all five series suggests that the first differences are stationary. These results are available from the authors upon request.

${ }^{11}$ The appropriate p-values are obtained from Hansen (1992a).

12 The appropriate p-values are obtained from MacKinnon (1994).

${ }^{13}$ Hansen and Lunde (2001) evaluate conditional variance forecasts from a variety of

GARCH type models of daily Deutchmark/US Dollar exchange rate and IBM stock prices using realized volatility calculated using intra-day returns.

${ }^{14}$ The authors would like to thank Peter Hansen for supplying Ox code that calculates the SPA test statistics and associated p-values. 